\title{
Fatty acid use in diving mammals: more than merely fuel
}

\author{
Stephen J. Trumble ${ }^{1 *}$ and Shane B. Kanatous ${ }^{2}$ \\ 1 Department of Biology, Baylor University, Waco, TA, USA \\ ${ }^{2}$ Department of Biology, Colorado State University, Ft. Collins, CO, USA
}

\section{Edited by:}

Andreas Fahlman, Texas A\&M Corpus Christi, USA

Reviewed by:

Tim Moerland, Kent State University, USA

Michael A. Menze, Eastern Illinois

University, USA

*Correspondence:

Stephen J. Trumble, Department of Biology, Baylor University, One Bear Place 97388, Waco, TX 76798, USA. e-mail: stephen_trumble@baylor.edu
Diving mammals, are under extreme pressure to conserve oxygen as well as produce adequate energy through aerobic pathways during breath-hold diving. Typically a major source of energy, lipids participate in structural and regulatory roles and have an important influence on the physiological functions of an organism. At the stoichiometric level, the metabolism of polyunsaturated fatty acids (PUFAs) utilizes less oxygen than metabolizing either monounsaturated fatty acids or saturated fatty acids (SFAs) and yields fewer ATP per same length fatty acid. However, there is evidence that indicates the cellular metabolic rate is directly correlated to the lipid composition of the membranes such that the greater the PUFA concentration in the membranes the greater the metabolic rate. These findings appear to be incompatible with diving mammals that ingest and metabolize high levels of unsaturated fatty acids while relying on stored oxygen. Growing evidence from birds to mammals including recent evidence in Weddell seals also indicates that at the whole animal level the utilization of PUFAs to fuel their metabolism actually conserves oxygen. In this paper, we make an initial attempt to ascertain the beneficial adaptations or limitations of lipids constituents and potential trade-offs in diving mammals. We discuss how changes in Antarctic climate are predicted to have numerous different environmental effects; such potential shifts in the availability of certain prey species or even changes in the lipid composition (increased SFA) of numerous fish species with increasing water temperatures and how this may impact the diving ability of Weddell seals.

Keywords: fatty acids, diving mammals, PUFA, ontogeny, lipids

\section{INTRODUCTION}

Diving mammals, such as the Weddell seal (Leptonychotes weddellii), are under extreme pressure to conserve oxygen as well as produce adequate energy through aerobic pathways during breathhold diving. It is recognized that diving mammals undergo a dive response involving apnea (cessation of breathing), bradycardia, and subsequent decreased cardiac output, as well as peripheral vasoconstriction (reduced blood flow or ischemic conditions in the working skeletal muscles) causing the animal to depend solely on a finite supply of oxygen stored internally. In other words, when diving mammals are active (foraging), they are holding their breath, their working muscles receive little to no blood flow, and they rely solely on internal stores of oxygen, to fuel, and sustain a lipid based aerobic metabolism. Therefore, dive duration can be directly correlated to the rate of oxygen utilization and any factors that affect the rate of oxygen consumption could alter dive times (Fahlman et al., 2008; du Dot et al., 2009; Williams et al., 2011; Shiomi et al., 2012).

While dependant on lipid and protein from a typically piscivorous prey source, lipids provide double the energy per mass when compared to protein and are important as a stored energy source as well as for thermoregulation and hydrodynamics (Castellini et al., 2009). More detailed use of lipids reveal a possible developmental role as well as preferential mobilization of specific fatty acids during lactation (Wheatley et al., 2008; Trumble et al., 2010). Trumble et al. (2010) reported that the primarily ice-based Weddell seal pup had increased polyunsaturated fatty acids (PUFAs) recovered from lipids associated with their skeletal muscle whereas saturated fatty acids (SFAs) were decreased when compared with adults. Assuming similar lipid consumption between age classes, these findings led to speculation that pups were metabolizing SFAs in greater amounts than the adult age class. While consuming a milk high in unsaturated fatty acids (UFA; Wheatley et al., 2008), it was hypothesized that these young seals increased their metabolic and energetic advantage (increased oxygen to metabolize SFA when compared to UFA and more energy per mass) to combat their high mass-specific heat loss and metabolic limitations of being an endothermic mammal in Antarctica. As these seals continued to mature to adults, the fatty acids recovered were primarily monounsaturated fatty acids (MUFAs), however, there appeared to be an exchange between SFA and PUFA between these age classes (Trumble et al., 2010). In this paper, we explain the stoichiometry associated with fatty acid metabolism and hypothesize on the advantages and disadvantages of these fatty acid groups, primarily PUFAs, in diving mammals inhabiting polar waters. Finally, we offer some speculation on potential disadvantages of metabolizing certain groups of fatty acids in a changing environment.

\section{OXYGEN AND DIVING}

The important role for the rate of oxygen consumption and diving was recently elucidated in emperor penguins (Aptenodytes forsteri; Shiomi et al., 2012). The results of this study indicated that once 
a certain amounts of work or numbers of flipper strokes were reached, the animals initiated their return to the surface regardless of the amount of time spent diving. To date, this is the strongest evidence that alteration in oxygen consumption or work effort significantly alter dive times. Along with the aforementioned emperor penguins, Weddell seals represent extreme examples of this breathhold model. These divers routinely dive under an ice ceiling, which offers less than $5 \%$ access to breathable surface area (Figure 1). This is in sharp contrast to open water divers such as elephant seals (Mirounga angustirostris) or other non-polar pinnieds. These constraints demand that the Antarctic divers be more tightly regulated with respect to their oxygen utilization; they must complete a dive cycle and find a breathing hole before their oxygen stores are depleted. Previous research has illustrated how these and open water divers are uniquely adapted to their environment and how energy is conserved even at the molecular level (Burns, 1996; Burns et al., 1998; Kanatous et al., 1999, 2001, 2002, 2008a,b; Burns et al.,
2005, 2007; Clark et al., 2006, 2007; Noren et al., 2008b; Ptitsyn et al., 2010; Trumble et al., 2010; Ponganis et al., 2011; Williams et al., 2011). For example, studies of adult Weddell seals, harbor seals (Phoca vitulina) and Steller sea lions (Euematopias jubatus) have revealed that their muscle adaptations to maintain a lipid based aerobic metabolism under the hypoxic conditions associated with breath-hold diving include: (1) an increased aerobic capacity (or one that is matched to routine levels of exertion), (2) a reliance on fatty acid catabolism for aerobic ATP production, (3) enhanced oxygen storage and diffusion capacity, and (4) a reduced dependency on blood-borne oxygen and metabolites (e.g., decreased capillary density) compared to terrestrial mammals (Davis et al., 1991; Davis and Kanatous, 1999; Kanatous et al., 1999, 2001, 2002). Recently, physiological studies have begun to describe the development of diving capacity and oxygen stores in diving mammals (Noren et al., 2004, 2005, 2006, 2008a; Clark et al., 2006, 2007; Kanatous et al., 2008a). Recent data have reported

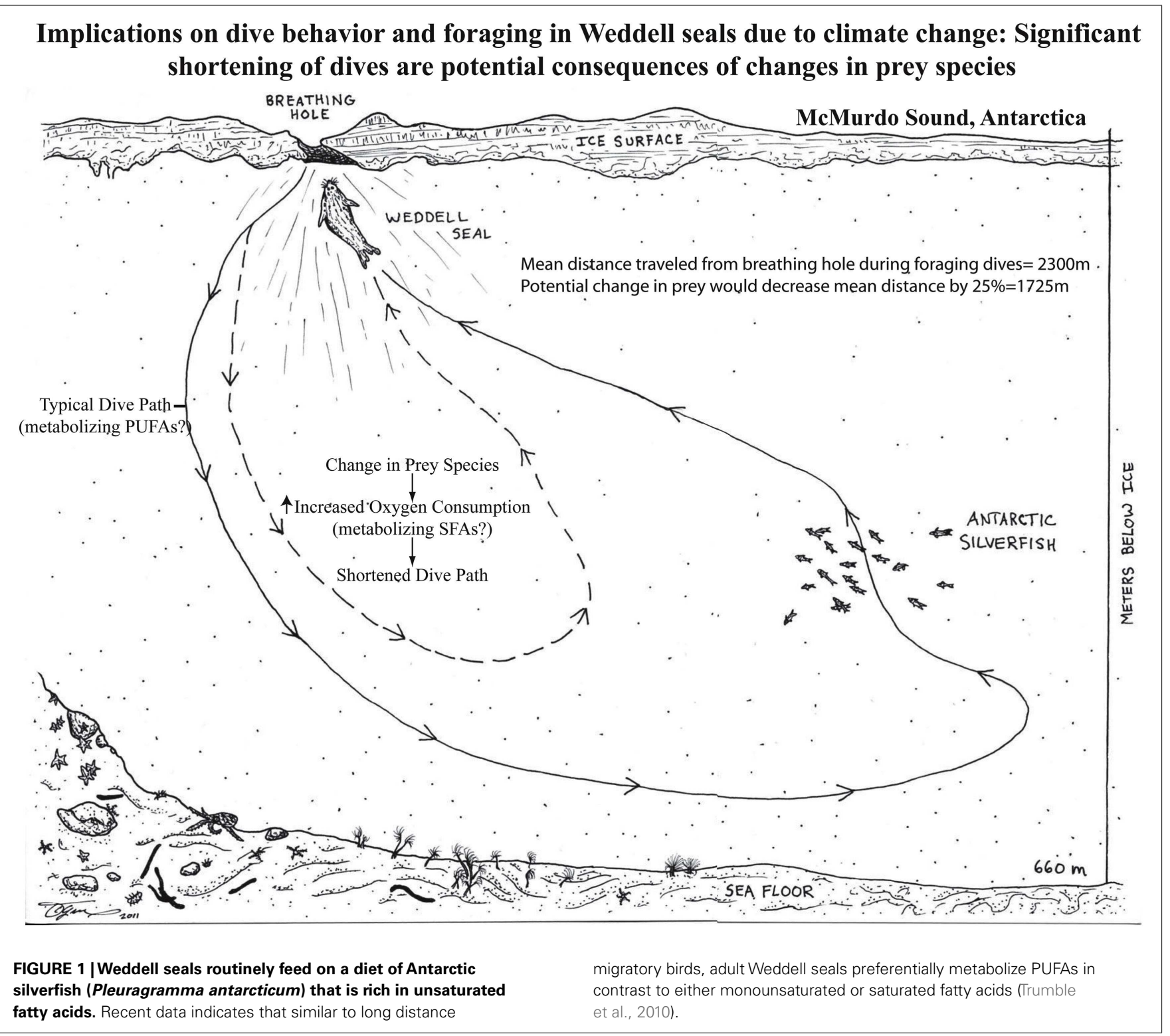


numerous physiological changes such as an increase in the concentration of myoglobin to levels $\sim 60 \%$ of those found in adults. These adaptations occur during weaning periods and are necessary for these animals to initiate independent foraging (Burns, 1996; Kanatous et al., 2008a).

In terms of skeletal muscle development, the cessation of weaning and commencement of diving in Weddell seals induces developmental changes in muscle physiology that parallel changes in activity. Preliminary microarray results indicate differential expression of RNA transcripts associated with various ontogenic signaling pathways, in addition to differences in transcripts associated with lipid metabolism, among age classes (Kanatous et al., 2008b; Ptitsyn et al., 2010). These previous findings mirrored results describing significant changes in the lipid composition and potential utilization of fatty acids in skeletal muscle during these developmental stages (Trumble et al., 2010). In addition, where this developmental trend of increasing exercise capacity occurs from birth in terrestrial mammals, we found that the skeletal muscle physiology of Weddell seal pups suggests a higher capacity for exercise than juveniles or adults. This is indicated by pups having the highest percentage of type I slow oxidative fibers as well as the highest mitochondrial volume densities of any age class. A relative lack of an increase in aerobic enzymes, however, indicates that these results may be due to an adaptation for enhanced non-shivering thermogenesis (Kanatous et al., 2008a). Furthermore, juveniles were recently shown to have the highest expression of myoglobin $\left(72.4 \pm 7\right.$ vs. $55.9 \pm 2.5$ and $35.5 \pm 3 \mathrm{mg} \mathrm{g}^{-1}$ wet mass muscle in adults and pups, respectively) supporting the hypothesis that myoglobin concentrations differ with behavioral differences in diving activity (Kanatous et al., 2008a).

\section{FATTY ACIDS AND STOICHIOMETRY}

Typically known as a major source of energy, lipids also participate in structural and regulatory roles that have an important influence on the physiological functions of an organism. As essential fatty acids, it is well known that PUFAs of $n-3$ and $n-6$ groups are considered the most powerful intracellular and intercellular mediators and modulators of the cell signaling network and cell membrane fluidity (important in polar habitats). The action of PUFAs has been shown to have various effects on immune and inflammatory processes (Puertollano et al., 2004). While the processes above are certainly important for a developing diving mammal, fatty acids play a large role in fueling metabolism and may provide insight into diving adaptations. For mammalian diver's it is imperative to conserve oxygen to maximize success of an intake of primarily unsaturated fats and proteins. This intake of UFAs and subsequent transport and oxidation within skeletal muscles (assuming skeletal muscle activity during diving) may to be an advantage to the diver. Specifically, the moles of oxygen needed to metabolize any particular SFA are slightly greater than that for a similar length UFA (MUFA and PUFA). This stoichiometry of oxygen consumption is based on the number of double bonds and thus hydrogen involved (see below for example). If extrapolated to the fatty acid groups (not the individual fatty acids) identified in Weddell seal blubber (14-24 carbon; Trumble et al., 2010), the mean moles of oxygen needed to oxidize PUFAs $\left(29 \mathrm{~mol} \mathrm{O}_{2} / \mathrm{FA}\right)$ is greater than MUFAs $\left(26 \mathrm{~mol} \mathrm{O}_{2} / \mathrm{FA}\right)$ and SFAs $\left(23 \mathrm{~mol} \mathrm{O}_{2} / \mathrm{FA}\right)$. Upon closer examination, a majority of saturated and unsaturated fatty acids recovered (percent of total) from the blubber (Wheatley et al., 2008) and muscle of Weddell seals are 18 carbons (18C) in length (>50\%, Trumble et al., 2010). Specifically, an 18C SFA containing 36 hydrogen atoms requires $(36 / 4)+18-1=26 \mathrm{~mol}$ of oxygen for complete oxidation whereas the most commonly recovered MUFA, 18:1, requires $25.5 \mathrm{~mol}$ and the most commonly recovered PUFA, 18:3 requires $25 \mathrm{~mol}$ of oxygen for complete oxidation. Based on mean percent fatty acid composition from Weddell seal pups (SFA, 28\%; UFA, 72\%), juveniles (SFA, 31\%; UFA, 69\%), and adults (SFA, 30\%; UFA 70\%; Trumble et al., 2010) and an estimated mean total percent blubber mass for each age class (Gales and Burton, 1987; Noren et al., 2008b; pups, $32 \pm 0.8 \%$; juveniles, $21.5 \pm 0.7 \%$; and adults, $23.9 \pm 0.7 \%$ ) estimates of moles of oxygen required to oxidize saturated and unsaturated fatty acids can be calculated (Figure 2). This may equate to UFA-oxygen conservation when compared with metabolizing similar amounts of SFAs in Weddell seal adults. While this alteration of oxygen consumption appears insignificant in terms of oxygen moles oxidized between these $18 \mathrm{C}$ fatty acids, when extrapolating to a $400-\mathrm{kg}$ adult (35\% muscle mass; Ponganis et al., 1993) and differences in mass-specific metabolic rates $\left(0.676 \mathrm{M}_{\mathrm{b}}{ }^{0.75} / \mathrm{kg}\right.$; Kleiber, 1975) metabolizing an unsaturated $18 \mathrm{C}$ fatty acid offers an increase of $\sim 30$ s of dive time (not taking activity budget into account) during a $30-\mathrm{min}$ dive. A dive time shortened by $30 \mathrm{~s}$ (assuming dive locomotion at $1-3 \mathrm{~m} / \mathrm{s}$ ), would shortened the distance covered by 30-90 m, which could significantly alter foraging or breathing hole location success.

The stoichiometric relationship between saturated and unsaturated fatty acids from an energy production (ATP) perspective also results in differences, which may also influence diving. Using the most common fatty acid recovered (18:1, Trumble et al., 2010), we surmise that the oxidation of unsaturated fatty acids requires additional auxiliary enzymes (isomerases and a reductase). This becomes important in that the double bonds formed in betaoxidation are trans as opposed to cis in naturally occurring unsaturated fatty acids. Specifically, an isomerase is required for breaking the double bond in MUFAs, which are typically between carbons 9 and 10 . Thus, oleate (18:1) requires three cycles of beta-oxidation with each cycle removing two carbons, replacing the double bond at the number 3 position. The hydratase of beta-oxidation requires the double bond to be in the trans configuration and at second carbon location. Therefore, the ATP count for MUFAs ( $>50 \%$ of total percent of FAs recovered) is two less than the fully saturated ana$\log$ because one fewer $\mathrm{FADH}_{2}$ is generated (for 18:0, there are 146 ATP produced; for 18:1 there would be 144 ATP produced). Further, to process the second double bond in a PUFA, for example $18: 2$, another reductase and isomerase are required. Since the double bonds are typically in the 9 and 12 positions, the three cycles of beta-oxidation can proceed as usual, resulting in the double bonds at the 3 and 6 positions. Beta-oxidation will then proceed to form a trans-2, cis-4 product. The mammalian version of the second auxiliary enzyme, another reductase, reduces this to a singly unsaturated product with a trans double bond in the 3 position. With this additional reductase involved, the ATP count will be three fewer than for a fully saturated version because, in addition to the loss of $\mathrm{FADH}_{2}$, one NADPH is used for this additional 


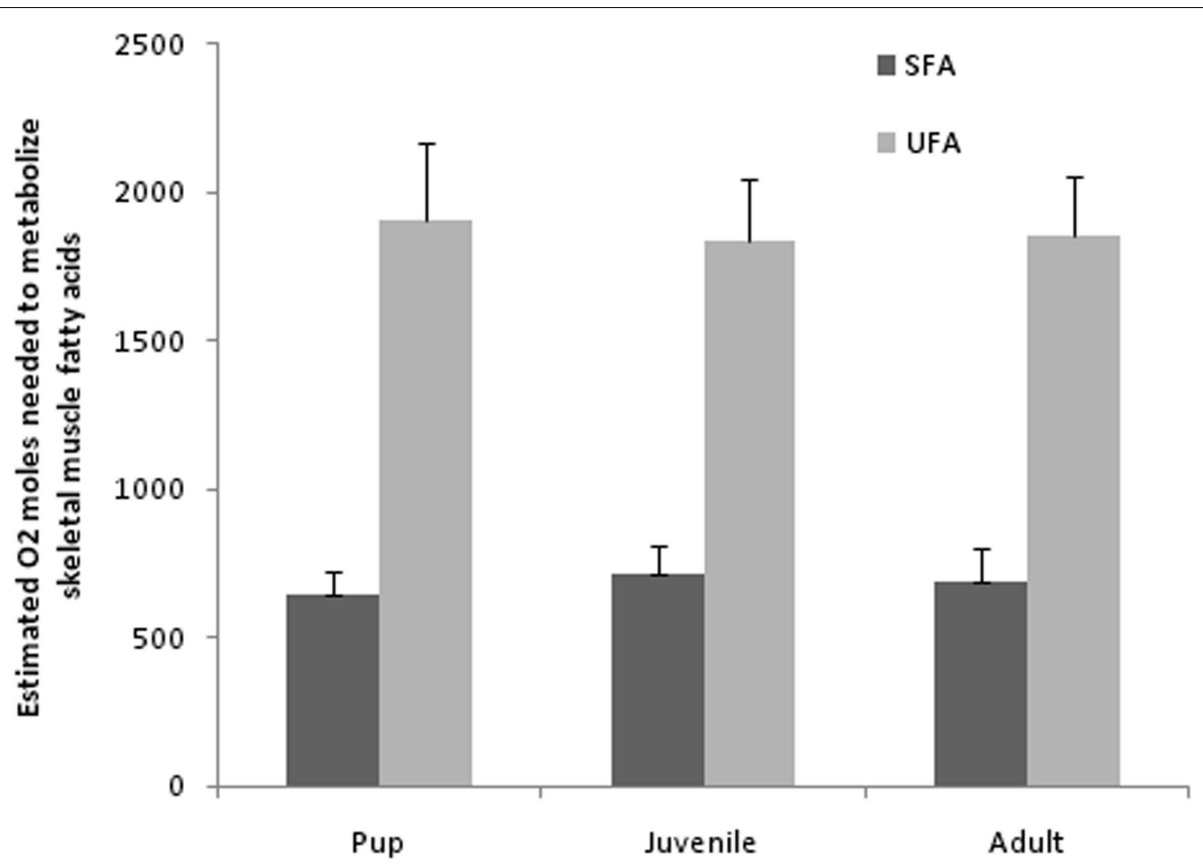

FIGURE 2 | Estimated moles of oxygen needed to completely oxidize saturated (SFA), and unsaturated (UFA) fatty acids recovered from Weddell seal skeletal muscles $(\boldsymbol{n}=\mathbf{2 0})$ in 2006. Calculations derived from mean moles of oxygen (see text) and mean lipid amounts in skeletal muscle (Trumble et al., 2010) among age groups and mean mass of age groups (estimates for blubber mass derived from Noren et al., 2008b) and mean total percent of fatty acids recovered. note: fatty acids include (SFA; C14:0-24:0), monounsaturated (MUFA; 14:1n-5, 16:1n-9, 16:1n-7, 18:1n-9, 18:1n-7, $18: 1 n-11,20: 1 n-9,20: 1 n-7,22: 1 n-11,22: 1 n-9,24: 1 n-9)$, and polyunsaturated (PUFA; 18:2n-6, 18:3n-6, 18:3n-3, 18:4n-3, 20:2n-9, $20: 2 n-6,20: 3 n-6,20: 4 n-6,20: 3 n-3,20: 4 n-3,20: 5 n-3,22: 4 n-6$, $22: 5 n-6,22: 5 n-3,22: 6 n-3)$. reductase. Thus, the ATP count for a fatty acid configured as 18:2 would only be 141 as compare to 146 from a saturated $18 \mathrm{C}$ fatty acid. While there may be a loss in ATP production by preferentially metabolizing UFAs as compared to SFAs, dives are more limited by oxygen than ATP thus the oxygen conservation may dramatically outweigh the differences in ATP production for these animals.

\section{THE FATTY ACID TRADE-OFF: MEMBRANE COMPOSITION}

The consumption of a high fat diet produces a surplus of NADH and $\mathrm{FADH}_{2}$, which subsequently increases the generation of reactive oxygen species (ROS). Indeed, a high fat diet has been shown to increase the rate of $\mathrm{H}_{2} \mathrm{O}_{2}$ (ROS species) production in skeletal muscle mitochondria (Nadal-Casellas et al., 2010). This production of ROS has been reported to contribute to the processes of aging as well as progression of numerous disorders such as Type II diabetes and Parkinson disease in mammals (Kang and Hamasaki, 2003). Ultimately, the increased rate of ROS production by the mitochondria results in mitochondrial dysfunction in skeletal muscle. However, recent studies have begun to elucidate the differential role of cellular membrane lipid composition in the susceptibility to ROS damage (Hulbert, 2008a,b, 2010; Montgomery et al., 2011). These studies have shown that membranes composed of higher concentrations of PUFAs have an increased susceptibility to ROS damage by lipid peroxidation, which ultimately shortens lifespan in animals. However, it has been speculated that membranes higher in MUFAs protect against ROS damage (Hulbert, 2010). Trumble et al. (2010) reported that greater than half of all the recovered fatty acids associated with the skeletal muscle of
Weddell seals were MUFAs. We speculate this increase in MUFA levels supports in ameliorating damage by ROS. New research also found that membranes of the relatively long-lived short-beaked echidna (Tachyglossus aculeatus) are more monounsaturated and less polyunsaturated than would be predicted from their body size which were hypothesized to ameliorate ROS damage and promote long life spans (Hulbert, 2008a,b, 2010). This association between PUFA membrane levels appears to be related to life span (Hulbert, 2010) as well as Basal metabolic rate (BMR) and appears to hold true for most terrestrial mammals and birds studied (Hulbert, 2008a,b, 2010).

Basal metabolic rate represents cellular living at a minimal cost within certain assumptions such that the mass-specific BMR has been shown to vary among species inversely related to body size. An idea proposed and developed by Hulbert and Else (1999) suggests that this variation in BMR is not only a function of body size but also directly related to cellular metabolic rate which is directly correlated to the lipid composition of the membranes (Hulbert and Else, 1999). Further, and mentioned above, there appears to be a direct positive correlation between PUFA levels in the membrane and a higher BMR. We report here for the first time, that Weddell seals appear to follow the concept proposed by Hulbert and Else (1999); PUFAs are increased in the skeletal muscle membrane of the smaller pup and decline with the larger animals (Figure 3). While unknown whether this switch in membrane fatty acids occurs during development in terrestrial mammals, we report that this metabolic switch in membrane composition occurs after pupping or lactation and seems to be transitioned 
in juveniles. In terrestrial mammals, higher levels of PUFAs have been reported in the membranes of relatively smaller mammals and have been associated with leakier membranes and more active pumps (Hulbert, 2010). This "PUFA-permeable prefigure" may add evidence to our recent findings that Weddell seal pups offset their thermal challenge of being an endothermic animals born into an extremely harsh environment of Antarctica through the use of increased and potentially uncoupled metabolism. In short, it appears that non-diving pups adopt the metabolic and cellular "benefits" of the relatively small terrestrial mammal PUFA rich membrane composition. At this time, we do not know the mechanisms involved with this membrane switch. However, it appears to coincide with development, or the physiological shift to adult divers. Further, as membrane PUFA levels change, MUFA and SFA levels increase in adult membrane composition for possible additional protection from ROS damage from proportionally high rates of sustained lipid metabolism and from the reperfusion of the muscles associated with the end of dives (Figure 3).

Interestingly, an additional "benefit" or adaptation of ingesting and metabolizing PUFAs, especially in adult diving mammals, may be its influence on heart rate. A report by Gudbjarnason et al. (1978) reported that the heart rate of animals, ranging from mice to whales, was directly related to the levels of $22: 6 n-3$ in their cardiac phospholipids (Gudbjarnason et al., 1978). Subsequently, it was determined that this increase in $22: 6 n-3$ was also positively correlated with increased $\mathrm{Ca}^{2+}$ ATPase activity in the cell (Infante, 1987) which led to the "membrane pacemaker theory" mentioned above (Hulbert and Else, 1999). This notion that heart rate is influenced by $n-3$ fatty acids has been pursued by several investigators with the general consensus that ingestion of $n-3$ fatty acids tend to lower resting heart rates (Christensen et al., 1999; Billman and Harris, 2011). Assuming that the relatively lower PUFA levels associated in the skeletal muscle lipids is a function of increased metabolizing of PUFAs and not a function of decreased PUFA intake, then our findings may indicate a preferential fatty acid adaptation to lower heart rate during diving. It should be mentioned that PUFAs cannot be formed de novo by mammalian cells and therefore must be obtained from the diet. Assuming a PUFA rich prey equal in proportion to what is found in milk (Wheatley et al., 2008) then our findings suggest PUFAs were preferentially mobilized by the muscle for energy and, more importantly, switch in levels in the skeletal muscle membranes. At this time, we can only speculate that this switch may suggest a regulation of desaturases or elongases associated with membrane lipid constituents. Further research is needed to confirm this hypothesis.

It has been reported that long distance migratory birds (Calidris pusilla) ingest a diet high in $n-3$ PUFA prior to migration, potentially acting as a molecular signal to prime flight muscles and increase oxygen efficiency while using less energy (Maillet and Weber, 2006; Piersma, 2011). Several studies contribute to this notion and suggest that PUFAs may affect the performance of skeletal muscles and locomotion in a variety of vertebrates (McKenzie et al., 1998; Helge et al., 2001; Infante et al., 2001; Valencak et al., 2003). We speculate PUFAs, especially $n-3$ 's, play an important role in the development of foraging from pup to adults and that these fatty acids may be functionally related to oxygen conservation, locomotor performance, life stage specific energetic demands and diving ability. In a recent study involving rats switched from a SFA diet to fish oil (high $n-3$ PUFAs) myocardial oxygen consumption, coronary flow and percent oxygen extraction was significantly reduced while maintaining integrity of contractile function in the heart muscle (Pepe and McLennan, 2007). The metabolic costs of foraging are critical components of the energy budget of animals and will have direct affect on the amount of prey they must obtain to survive. This is especially true for breath-hold deep divers; where any increases in the metabolic costs will significantly alter their dive times and foraging success. As stated above, our recent data indicates that similar

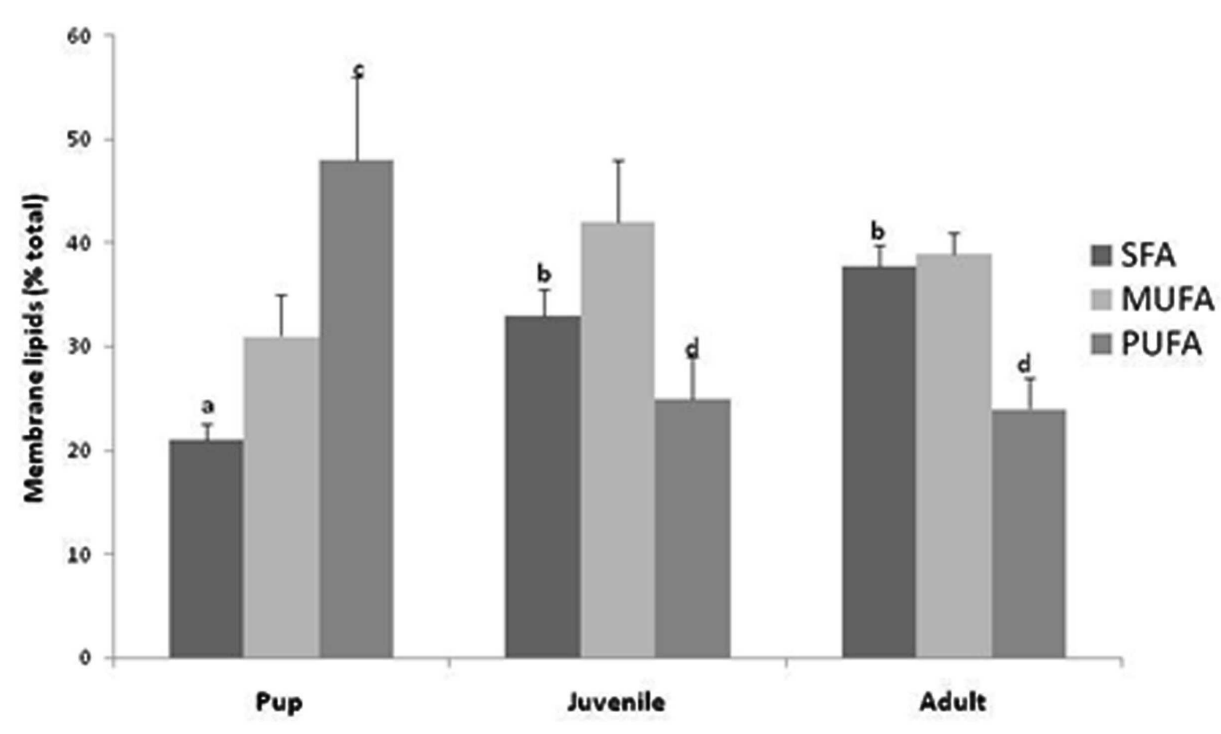

FIGURE 3 | Membrane (phospholipids) fatty acids (saturated, SFA; monounsaturated, MUFA; and polyunsaturated, PUFA) in Weddell seal skeletal muscle (pup, $\boldsymbol{n}=\mathbf{5}$; juvenile, $\boldsymbol{n = 5}$; adult, $\boldsymbol{n = 5}$ ). Differences in lower case letters denotes statistical differences among age classes $(p<0.05)$. 
to long distance migratory birds, adult Weddell seals preferentially metabolize oxygen-conserving PUFAs in contrast to either MUFAs or SFAs, which enable the seals to preserve their limited oxygen resources during diving. An important area of future research will be elucidating the molecular controls that regulate this switch in metabolic fuel during ontogeny.

\section{FATTY ACIDS AS REGULATORY SIGNALS}

Because myoglobin has been shown to increase during the weaning period of both penguins and seals before they initiate diving (Burns et al., 2005, 2007; Clark et al., 2007) the potential for myoglobins regulation to be dependent on its interplay with specific fatty acids seems plausible. Indeed, recent evidence has shown that the amount and type of lipids act as important initial regulators of myoglobin in diving mammals (De Miranda Jr. et al., 2012) with some indication of secondary regulation by activity level and calcium signaling (Kanatous et al., 2008b, 2009; Ptitsyn et al., 2010). In comparative animal studies, an increase of $n-3$ PUFAs or a high $n-3$ to $n-6$ ratio of fatty acids was shown to prompt increases in calcium transport and calcium absorption in PUFA-deficient rats (Kruger and Horrobin, 1997; Weiss et al., 2005). It has been established in terrestrial animals and diving mammals that calcium signaling, as well as its downstream targets of calcineurin and NFAT, plays an important role in determining fiber type distribution, aerobic capacity and myoglobin concentrations in skeletal muscles (Chin et al., 1998; Spangenburg and Booth, 2003). Recent evidence from our labs indicates this increase of myoglobin expression in weaning animals before they start diving may be initiated through an activity and calcium independent pathway. While further studies in cell culture may yield a more specific response to certain fatty acids, our current research strongly suggests that the pre-dive increases in myoglobin of divers during weaning may be associated with changes in the lipid composition of the milk associated with nursing (De Miranda Jr. et al., 2012). Additional results from our labs suggests that the when compared to mouse samples (Mus musculus), marine mammal species demonstrated increased levels of sphingolipids and ceramides in the cell membrane. Specifically, sphingomyelin, phosphatidylcholine, ceramide, and sphingosine were elevated in the cellular membranes. While preliminary, these differences may result in changes in total cellular metabolism since these lipid constituents are known to be involved in cell signaling pathways.

\section{REFERENCES}

Billman, G. E., and Harris, W. S. (2011). Effect of dietary omega3 fatty acids on the heart rate and the heart rate variability responses to myocardial ischemia or submaximal exercise. Am. J. Physiol. Heart Circ. Physiol. 300, H2288-H2299.

Burns, J. (1996). The development of diving behavior in juvenile Weddell seals: pushing physiological limits in order to survive. Can. J. Zool. 77, 737-747.

Burns, J. M., Costa, D. P., Frost, K., and Harvey, J. T. (2005). Development of

\section{CONCLUSION}

While certainly incomplete, we have pointed out some potential advantages/disadvantages of metabolizing fatty acids in diving mammals. While it has been described that fatty acids in polar marine mammals are elevated in C16-C24 UFAs, we make an initial attempt to ascertain the beneficial adaptations or limitations of these lipids constituents. At the stoichiometric level, the metabolism of UFAs may be correlated to oxygen conservation (Suarez, 2011; Weber, 2011) while producing fewer ATP. There is evidence that indicates cellular metabolic rate is directly correlated to the PUFA composition of the membranes: birds to terrestrial mammals utilize PUFAs to conserve oxygen, possibly through lowering cardiac rate. Additionally, we speculate that ontogenetic tradeoffs of fatty acids in the skeletal muscle and cellular membrane may play a vital role in the regulating changes in metabolism and establishing certain skeletal muscle adaptations (i.e., myoglobin) to diving in Weddell seals. As a current point of discussion, changes in Antarctic climate are predicted to have numerous different environmental effects; such potential shifts in the availability of certain prey species or even changes in the lipid composition (increased SFA) of numerous fish species with increasing water temperatures (Phleger et al., 1999). As we have calculated above, a slight change in fatty acid saturation could alter the diving capacity of Weddell seals. In order to clearly understand the physiology of these divers and predict how these animals will react to physiological challenges, we must understand the full suite of adaptations; from potential shifts in metabolic fuels that could affect dive times and foraging ability to understanding the molecular switches to become an efficient diver. Further research is required on the role specific lipids have on regulating homeostatic pathways. Our understanding of the role of lipids in regulating the homeostasis of the animals is in its initial stages.

\section{ACKNOWLEDGMENTS}

The authors would like to thanks A. Fahlman for the invitation to publish in the Scholander Legacy. This work was supported by NSF Office of Polar Programs grants (OPP-0125475 and OPP-0440713) awarded to Shane B. Kanatous. All samples were collected under MMPA \#10751788-00. We wish to thank all the personnel at Raytheon Polar services for their outstanding support as well as several colleagues for their field and lab assistance; T. Hawke, S. Noren, R. Watson, and J. Davis.

isotope analysis. Polar Biol. 19, 272-282.

Castellini, M. A., Trumble, S. J., Mau, T. L., Yochem, P. K., Stewart, B. S., and Koski, M. A. (2009). Body and blubber measurements of Antarctic pack-ice seals: Implications for the control of body condition and blubber regulation. Physiol. Biochem. Zool. 82, 113-120.

Chin, E. R., Olson, E. N., Richardson, J. A., Yang, Q., Humphries, C. Shelton, J. M., Wu, H., Zhu, W. Bassel-Duby, R., and Williams, R. S. (1998). A calcineurin-dependent transcriptional pathway controls skeletal muscle fiber type. Genes Dev. 12, 2499-2509.

Christensen, J. H., Christensen, M. S., Dyerberg, J., and Schmidt, E. B. (1999). Heart rate variability and fatty acid content of blood cell membranes: a dose-response study with n-3 fatty acids. Am. J. Clin. Nutr. 70, 331-337.

Clark, C. A., Burns, J. M., Schreer, J. F., and Hammill, M. O. (2006). Erythropoietin concentration in developing harbor seals (Phoca vitulina). Gen. Comp. Endocrinol. 147, 262-267. 
Clark, C. A., Burns, J. M., Schreer, J. F., and Hammill, M. O. (2007). A longitudinal and cross-sectional analysis of total body oxygen store development in nursing harbor seals (Phoca vitulina). J. Comp. Physiol. B 177, 217-227.

Davis, R. W., Castellini, M. A., Williams, T. M., and Kooyman, G. L. (1991). Fuel homeostasis in the harbor seal during submerged swimming. J. Comp. Physiol. B 160, 627-635.

Davis, R. W., and Kanatous, S. B. (1999). Convective oxygen transport and tissue oxygen consumption in Weddell seals during aerobic dives. J. Exp. Biol. 202(Pt 9), 1091-1113.

De Miranda, M. A. Jr., Schlater, A. E., Green, T. L., and Kanatous, S. B. (2012). In the face of hypoxia: myoglobin increases in response to hypoxic conditions and lipid supplementation in cultured Weddell seal skeletal muscle cells J. Exp. Biol. 215, 806-813.

du Dot, T. J., Rosen, D. A., Richmond, J. P., Kitaysky, A. S., Zinn, S. A., and Trites, A. W. (2009). Changes in glucocorticoids, IGF-I and thyroid hormones as indicators of nutritional stress and subsequent refeeding in Steller sea lions (Eumetopias jubatus). Comp. Biochem. Physiol. Part A Mol. Integr. Physiol. 152, 524-534.

Fahlman, A., Svard, C., Rosen, D. A., Jones, D. R., and Trites, A. W. (2008). Metabolic costs of foraging and the management of $\mathrm{O} 2$ and $\mathrm{CO} 2$ stores in Steller sea lions. J. Exp. Biol. 211, 3573-3580.

Gales, N. J., and Burton, H. R. (1987). Ultrasonic measurement of blubber thickness of the southern elephant seal, Mirounga leonina (Linn.). Aust. J. Zool. 35, 207-217.

Gudbjarnason, S., Doell, B., Oskardottir, G., and Hallgrimsson, J. (1978). Modification of Cardiac Phospholipids and Catecholamine Stress Tolerance. Amsterdam: Elsevier.

Helge, J. W., Wu, B. J., Willer, M., Daugaard, J. R., Storlien, L. H., and Kiens, B. (2001). Training affects muscle phospholipid fatty acid composition in humans. J. Appl. Physiol. 90, 670-677.

Hulbert, A. J. (2008a). Explaining longevity of different animals: is membrane fatty acid composition the missing link? Age (Dordr.) 30, 89-97.

Hulbert, A. J. (2008b). The links between membrane composition, metabolic rate and lifespan. Comp. Biochem. Physiol. Part A Mol. Integr. Physiol. 150, 196-203.
Hulbert, A. J. (2010). Metabolism and longevity: is there a role for membrane fatty acids? Integr. Comp. Biol. 50, 808-817.

Hulbert, A. J., and Else, P. L. (1999). Membranes as possible pacemakers of metabolism. J. Theor. Biol. 199, 257-274.

Infante, J. P. (1987). Docosahexaenoatecontaining phospholipids in sarcoplasmic reticulum and retinal photoreceptors. A proposal for a role in $\mathrm{Ca} 2+$-ATPase calcium transport. Mol. Cell. Biochem. 74, 111-116.

Infante, J. P., Kirwan, R. C., and Brenna, J. T. (2001). High levels of docosahexaenoic acid (22:6n3)-containing phospholipids in high-frequency contraction muscles of hummingbirds and rattlesnakes. Comp. Biochem. Physiol. B Biochem. Mol. Biol. 130, 291-298.

Kanatous, S. B., Davis, R. W., Watson, R., Polasek, L., Williams, T. M., and Mathieu-Costello, O. (2002). Aerobic capacities in the skeletal muscles of Weddell seals: key to longer dive durations? J. Exp. Biol. 205, 3601-3608.

Kanatous, S. B., DiMichele, L. V., Cowan, D. F., and Davis, R. W. (1999). High aerobic capacities in the skeletal muscles of pinnipeds: adaptations to diving hypoxia. J. Appl. Physiol. 86, 1247-1256.

Kanatous, S. B., Elsner, R., and MathieuCostello, O. (2001). Muscle capillary supply in harbor seals. J. Appl. Physiol. 90, 1919-1926.

Kanatous, S. B., Hawke, T. J., Trumble, S. J., Pearson, L. E., Watson, R. R., Garry, D. J., Williams, T. M., and Davis, R. W. (2008a). The ontogeny of aerobic and diving capacity in the skeletal muscles of Weddell seals. J. Exp. Biol. 211, 2559-2565.

Kanatous, S. B., Pearson, L. E., and Cable, A. E. (2008b). "How do you build a marine carnivore? The potential of microarray and proteomic techniques to identify the molecular regulation of the ontogeny of skeletal muscle adaptations in Weddell seals (Leptonychotes weddellii)," in Molecules to Migration: The Pressures of Life 4th CPB Meeting in Africa: Mara 2008, eds S. Morris and A. Vosloo (Bologna: Medimond Publishing Co.), 395-407.

Kanatous, S. B., Mammen, P. P., Rosenberg, P. B., Martin, C. M., White, M. D., Dimaio, J. M., Huang, G., Muallem, S., and Garry, D. J. (2009). Hypoxia reprograms calcium signaling and regulates myoglobin expression. Am. J. Physiol. Cell Physiol. 296, C393-C402.

Kang, D., and Hamasaki, N. (2003). Mitochondrial oxidative stress and mitochondrial DNA. Clin. Chem. Lab. Med. 41, 1281-1288.

Kleiber, M. (1975). The Fire of Life. Huntington, NY: Robert E. Krieger Publishing Co.

Kruger, M. C., and Horrobin, D. F. (1997). Calcium metabolism, osteoporosis and essential fatty acids: a review. Prog. Lipid Res. 36, 131-151.

Maillet, D., and Weber, J. M. (2006). Performance-enhancing role of dietary fatty acids in a long-distance migrant shorebird: the semipalmated sandpiper. J. Exp. Biol. 209, 2686-2695.

McKenzie, D. J., Higgs, D. A., Dosanjh, B. S., Deacon, G., and Randall, D. J. (1998). Dietary fatty acid composition influences swimming performance in Atlantic salmon (Salmo salar) in seawater. Fish Physiol. Biochem. 19, 111-122.

Montgomery, M. K., Hulbert, A. J., and Buttemer, W. A. (2011). The long life of birds: the rat-pigeon comparison revisited. PLoS ONE 6, e24138. doi:10.1371/journal.pone.0024138

Nadal-Casellas, A., Amengual-Cladera, E., Proenza, A. M., Llado, I., and Gianotti, M. (2010). Long-term high-fat-diet feeding impairs mitochondrial biogenesis in liver of male and female rats. Cell. Physiol. Biochem. 26, 291-302.

Noren, S. R., Biedenbach, G., and Edwards, E. F. (2006). Ontogeny of swim performance and mechanics in bottlenose dolphins (Tursiops truncatus). J. Exp. Biol. 209, 4724-4731.

Noren, S. R., Boness, D. J., Iverson, S. J., McMillan, J., and Bowen, W. D. (2008a). Body condition at weaning affects the duration of the postweaning fast in gray seal pups (Halichoerus grypus). Physiol. Biochem. Zool. 81, 269-277.

Noren, S. R., Pearson, L. E., Davis, J., Trumble, S. J., and Kanatous, S. B. (2008b). Different thermoregulatory strategies in nearly weaned pup, yearling, and adult Weddell seals (Leptonychotes weddelli). Physiol. Biochem. Zool. 81, 868-879.

Noren, S. R., Cuccurullo, V., and Williams, T. M. (2004). The development of diving bradycardia in bottlenose dolphins (Tursiops truncatus). J. Comp. Physiol. B 174, 139-147.

Noren, S. R., Iverson, S. J., and Boness, D. J. (2005). Development of the blood and muscle oxygen stores in gray seals (Halichoerus grypus): implications for juvenile diving capacity and the necessity of a terrestrial postweaning fast. Physiol. Biochem. Zool. 78, 482-490.

Pepe, S., and McLennan, P. L. (2007). (n-3) Long chain PUFA dosedependently increase oxygen utilization efficiency and inhibit arrhythmias after saturated fat feeding in rats. J. Nutr. 137, 2377-2383.

Phleger, C. F., Nichols, P. D., Erb, E., and Williams, R. (1999). Lipids of the notothenioid fishes Trematomus spp. and Pagothenia borchgrevinki from East Antarctica. Polar Biol. 22, 241-247.

Piersma, T. (2011). Why marathon migrants get away with high metabolic ceilings: towards an ecology of physiological restraint. J. Exp. Biol. 214, 295-302.

Ponganis, P. J., Kooyman, G. L., and Castellini, M. A. (1993). Determinants of the aerobic dive limit of Weddell seals: analysis of diving metabolic rates, postdive end tidal PO2s, and blood and muscle oxygen stores. Physiol. Zool. 66, 732-749.

Ponganis, P. J., Meir, J. U., and Williams, C. L. (2011). In pursuit of Irving and Scholander: a review of oxygen store management in seals and penguins. J. Exp. Biol. 214, 3325-3339.

Ptitsyn, A., Schlater, A., and Kanatous, S. (2010). Transformation of metabolism with age and lifestyle in Antarctic seals: a case study of systems biology approach to cross-species microarray experiment. BMC Syst. Biol. 4, 133. doi:10.1186/1752-05094-133

Puertollano, M. A., Puertollano, E., Ruiz-Bravo, A., Jimenez-Valera, M., De Pablo, M. A., and De Cienfuegos, G. A. (2004). Changes in the immune functions and susceptibility to Listeria monocytogenes infection in mice fed dietary lipids. Immunol. Cell Biol. 82, 370-376.

Shiomi, K., Sato, K., and Ponganis, P. J. (2012). Point of no return in diving emperor penguins: is the timing of the decision to return limited by the number of strokes? J. Exp. Biol. 215, 135-140.

Spangenburg, E. E., and Booth, F W. (2003). Molecular regulation of individual skeletal muscle fibre types. Acta Physiol. Scand. 178, 413-424.

Suarez, R. (2011). The biology of energy expenditure. J. Exp. Biol. 214, 163.

Trumble, S. J., Noren, S. R., Cornick, L. A., Hawke, T. J., and Kanatous, 
S. B. (2010). Age-related differences in skeletal muscle lipid profiles of Weddell seals: clues to developmental changes. J. Exp. Biol. 213, 1676-1684.

Valencak, T. G., Arnold, W., Tataruch, F., and Ruf, T. (2003). High content of polyunsaturated fatty acids in muscle phospholipids of a fast runner, the European brown hare (Lepus europaeus). J. Comp. Physiol. B Biochem. Syst. Environ. Physiol. 173, 695-702.

Weber, J. M. (2011). Metabolic fuels: regulating fluxes to select mix. J. Exp. Biol. 214, 286-294.
Weiss, L. A., Barrett-Connor, E., and von Muhlen, D. (2005). Ratio of n-6 to $n-3$ fatty acids and bone mineral density in older adults: the Rancho Bernardo Study. Am. J. Clin. Nutr. 81, 934-938.

Wheatley, K. E., Nichols, P. D., Hindell, M. A., Harcourt, R. G., and Bradshaw, C. J. (2008). Differential mobilization of blubber fatty acids in lactating Weddell seals: evidence for selective use. Physiol. Biochem. Zool. 81, 651-662.

Williams, C. L., Meir, J. U., and Ponganis, P. J. (2011). What triggers the aerobic dive limit? Patterns of muscle oxygen depletion during dives of emperor penguins. J. Exp. Biol. 214, 1802-1812.

Conflict of Interest Statement: The authors declare that the research was conducted in the absence of any commercial or financial relationships that could be construed as a potential conflict of interest.

Received: 09 February 2012; accepted: 18 May 2012; published online: 13 June 2012 .
Citation: Trumble SJ and Kanatous SB (2012) Fatty acid use in diving mammals: more than merely fuel. Front. Physio. 3:184. doi: 10.3389/fphys.2012.00184

This article was submitted to Frontiers in Aquatic Physiology, a specialty of Frontiers in Physiology.

Copyright (c) 2012 Trumble and Kanatous. This is an open-access article distributed under the terms of the Creative Commons Attribution Non Commercial License, which permits noncommercial use, distribution, and reproduction in other forums, provided the original authors and source are credited. 